\title{
BMJ Open Lessons learned from ramping up a Canadian Take Home Naloxone programme during a public health emergency: a mixed-methods study
}

\author{
Sympascho Young, ${ }^{1}$ Sierra Williams, ${ }^{2,3}$ Michael Otterstatter, ${ }^{2,4}$ Jennifer Lee, ${ }^{4}$ \\ Jane Buxton ${ }^{2,4}$
}

To cite: Young S, Williams S, Otterstatter M, et al. Lessons learned from ramping up a Canadian Take Home Naloxone programme during a public health emergency: a mixedmethods study. BMJ Open 2019;9:e030046. doi:10.1136/ bmjopen-2019-030046

- Prepublication history and additional material for this paper are available online. To view these files, please visit the journal online (http://dx.doi org/10.1136/bmjopen-2019030046).

Received 25 February 2019 Revised 06 September 2019 Accepted 17 September 2019

Check for updates

(c) Author(s) (or their employer(s)) 2019. Re-use permitted under CC BY-NC. No commercial re-use. See rights and permissions. Published by BMJ.

${ }^{1}$ Faculty of Medicine, University of British Columbia, Vancouver, British Columbia, Canada ${ }^{2}$ Harm Reduction, BC Centre for Disease Control, Vancouver, British Columbia, Canada ${ }^{3}$ Faculty of Health Sciences, Simon Fraser University, Burnaby, BC, Canada

${ }^{4}$ School of Population and Public Health, University of British Columbia, Vancouver, British Columbia, Canada

Correspondence to

Jane Buxton;

Jane.Buxton@bccdc.ca

\section{ABSTRACT}

Objectives This study describes the 2016 expansion of the British Columbia Take Home Naloxone (BCTHN) programme quantitatively and explores the challenges, facilitators and successes during the ramp up from the perspectives of programme stakeholders.

Design Mixed-methods study.

Setting The BCTHN programme was implemented in 2012 to reduce opioid overdose deaths by providing naloxone kits and overdose recognition and response training in $\mathrm{BC}$, Canada. An increase in the number of overdose deaths in 2016 in BC led to the declaration of a public health emergency and a rapid ramp up of naloxone kit production and distribution. BCTHN distributes naloxone to the five regional health authorities of $\mathrm{BC}$.

Participants Focus groups and key informant interviews were conducted with 18 stakeholders, including BC Centre for Disease Control staff, urban and rural site coordinators, and harm reduction coordinators from the five regional health authorities across BC.

Primary and secondary outcome measures Take Home Naloxone (THN) programme activity, qualitative themes and lessons learnt were identified.

Results In 2016, BCTHN responded to a 20 -fold increase in demand of naloxone kits and added over 300 distribution sites. Weekly numbers of overdose events and overdose deaths were correlated with increases in THN kits ordered the following week, during 2013-2017. Challenges elicited include forecasting demand, operational logistics, financial, manpower and policy constraints. Facilitators included outsourcing kit production, implementing standing orders and policy changes in naloxone scheduling, which allowed for easier hiring of staff, reduced paperwork and expanded client access.

Conclusion For THN programmes preparing for potential increases in naloxone demand, we recommend creating an online database, implementing standing orders and developing online training resources for standardised knowledge translation to site staff and clients.

\section{INTRODUCTION}

In the recent years, there has been a large global increase in mortality and morbidity rates due to opioid overdose. While opioid deaths are drawing media attention in North
Strengths and limitations of this study

To the best of our knowledge, this is the first study to describe the ramp up of a state or provincial level naloxone distribution programme in response to an overdose crisis.

- We make recommendations that can be used in designing, implementing and expanding Take Home Naloxone (THN) programmes, based on interviews from key stakeholders of the longest-running Canadian provincial THN programme.

- Our quantitative analysis showed time-series relationships among THN programme activity, overdose events and deaths; however, these statistical associations do not necessarily imply direct causal relationships.

America, it has also been rising in countries in Asia, Europe and Oceania. ${ }^{1}$ Opioid overdose deaths are preventable through timely administration of naloxone, a potent mu-opioid antagonist that reverses potentially fatal opioid-induced respiratory depression. Community-based distribution of naloxone kits through Take Home Naloxone (THN) programmes was first proposed and implemented in $1996 .{ }^{2}$ These programmes train participants such as people who use opioids and their family members and friends to recognise signs of overdose and to respond appropriately such as assessing airway, ventilation and administering naloxone..$^{3-5}$ McDonald and Strang conducted a global systematic review of 22 THN programmes in 2016, showing that they cause a reduction in overdose mortality among programme participants and communities. ${ }^{6}$

The British Columbia Take Home Naloxone (BCTHN) programme was implemented in 2012 by the BC Centre for Disease Control (BCCDC) funded through the provincial ministry of health. It is the longest running 


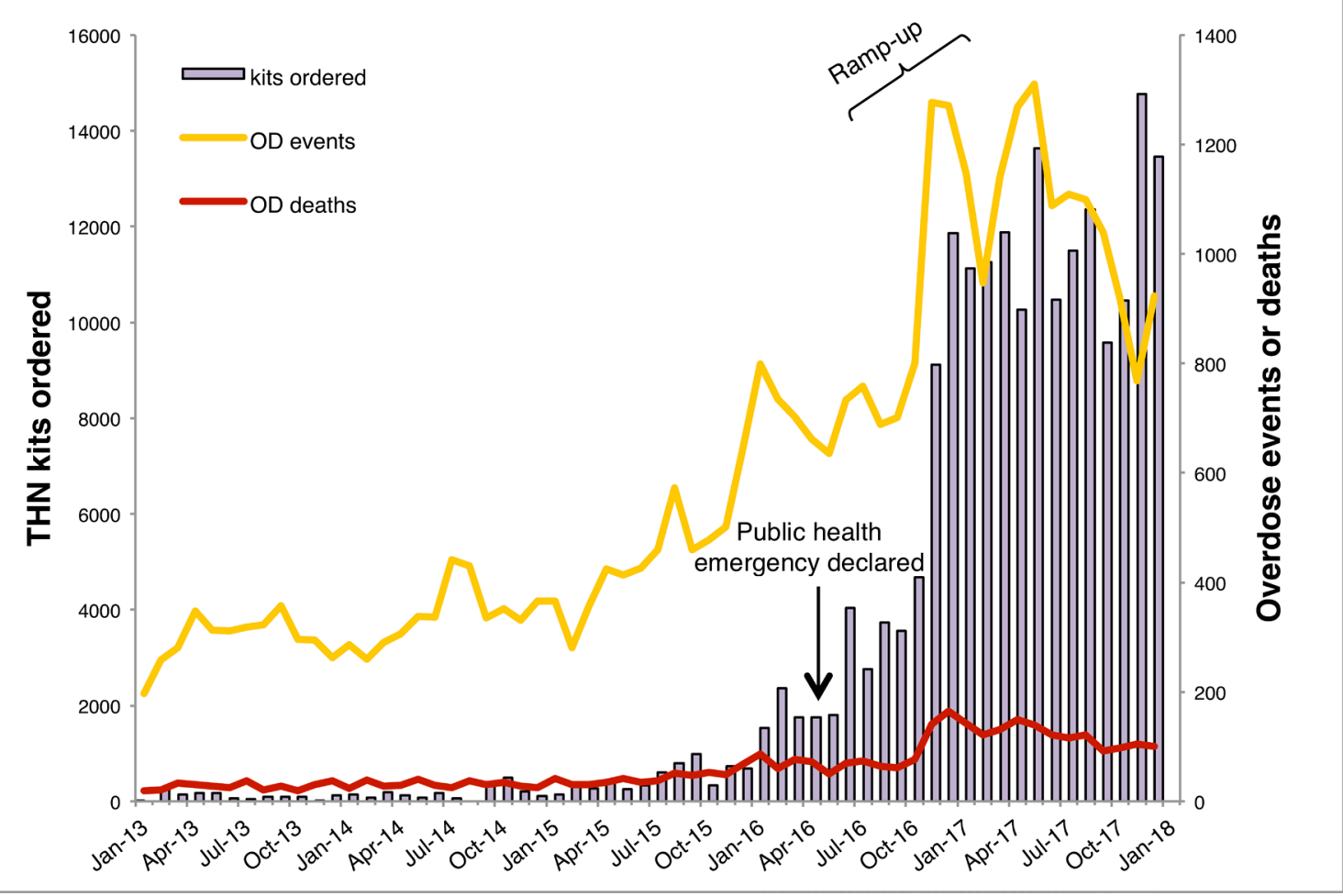

Figure 1 The number of illicit drug overdose events and deaths in British Columbia and THN kits ordered are plotted monthly from January 2013 to December 2017. OD, overdose; THN, Take Home Naloxone.

provincial programme of its kind in Canada, providing overdose response training and naloxone kits free of charge to all participants. Of the provinces in Canada, British Columbia (BC) has been most heavily affected by the opioid crisis, with a death rate of 20.6 per 100000 compared with an average of 7.8 per 100000 across Canada. ${ }^{7}$ A growing number of overdoses prompted the BC Provincial Health Officer to declare a Public Health Emergency on 14 April 2016. ${ }^{8}$ Despite public health measures, overdose deaths continued to surge in BC (figure 1), more than doubling between September and December 2016, causing an unexpected demand in naloxone kits and the need for BCTHN to rapidly ramp up the programme in response.

This article describes the ramp up using programme administration data and examines prior overdose events as a predictor of future demand for naloxone kits. In addition, we examine the challenges and successes experienced during the ramp up from the perspective of staff and stakeholders, providing valuable lessons for THN programmes that require sudden expansion in the midst of this global opioid crisis. To the best of our knowledge, this is the first study describing the ramp up of a state or provincial level naloxone distribution programme in response to an overdose crisis.

\section{METHODS}

\section{Patient and public involvement}

The BCTHN programme was developed in 2012 with input from people who use drugs (PWUD). The programme continues to be responsive to the needs and concerns of naloxone kit users through a community advisory board and regular programme evaluations. ${ }^{39}$ However, this study sought to explore the perspectives of programme stakeholders who were directly involved in kit distribution and affected by the BCTHN ramp up. These stakeholders were consulted during development of a logic model on which interview guides were based and for assistance in participant recruitment. Results were brought back to stakeholders and validated for completeness and accuracy.

\section{Setting}

The BCCDC Harm Reduction Programme operates BCTHN and is responsible for developing training materials, enrolling THN sites and supplying naloxone kits to registered sites. Naloxone kits are assembled by staff in the BCCDC Pharmacy. Each kit includes three ampules of $1 \mathrm{~mL}$ naloxone $0.4 \mathrm{mg} / \mathrm{mL}$, three safety needles for intramuscular injection, ampule snappers, non-latex gloves, a rescue-breathing barrier and an overdose response information form. THN sites are existing community agencies that receive kits and training from BCCDC. They are responsible for training clients and distributing kits. The programme operations have been published previously. ${ }^{3}$ Roles are described in more detail in table 1.

\section{Quantitative methods}

Quantitative data were extracted from an existing BCTHN database, which includes records of naloxone kit orders, 
Table 1 Characteristics of interviewed staff and stakeholders

\begin{tabular}{|c|c|c|c|c|}
\hline Staff* & Responsibilities & $\begin{array}{l}\text { Participated/ } \\
\text { invited } n / N\end{array}$ & Rural & Urban \\
\hline $\begin{array}{l}\text { BCCDC Harm } \\
\text { Reduction Lead }\end{array}$ & Direct and oversee the THN programme & $1 / 1$ & $\mathrm{n} / \mathrm{a}$ & $\mathrm{n} / \mathrm{a}$ \\
\hline $\begin{array}{l}\text { BCCDC Harm } \\
\text { Reduction Staff }\end{array}$ & $\begin{array}{l}\text { Administration of the programme: answer queries, data entry } \\
\text { and surveillance, epidemiology, site approval and processing kit } \\
\text { orders, developing training materials }\end{array}$ & $4 / 4$ & $\mathrm{n} / \mathrm{a}$ & $\mathrm{n} / \mathrm{a}$ \\
\hline $\begin{array}{l}\text { Harm Reduction } \\
\text { Coordinators } \ddagger\end{array}$ & Organise naloxone training for THN educators and site staff & $6 / 11$ & 3 & 3 \\
\hline $\begin{array}{l}\text { THN Site } \\
\text { Coordinators§ }\end{array}$ & $\begin{array}{l}\text { Train clients on overdose recognition and response, distribute } \\
\text { naloxone kits to clients, collect data and order kits from BCCDC }\end{array}$ & $3 / 6 \uparrow$ & 1 & 2 \\
\hline
\end{tabular}

*Only staff involved with BCTHN during ramp up were invited to participate.

†BCCDC Pharmacy has many roles in addition to BCTHN, such as ordering, packaging and distribution of vaccines and pharmaceuticals for BCCDC's other programmes.

$\ddagger$ Harm reduction coordinators report directly to their respective five provincial health authorities.

$\S$ THN sites include but are not limited to public health units, community health centres, peer resource centres, hospital emergency departments, detox centres and supervised consumption sites.

I) Only site coordinators who attended the June 2017 THN community advisory board meeting and who were involved in the programme during the ramp up period were invited to participate in this study $(n=6)$.

BCCDC, BC Centre for Disease Control; BCTHN, British Columbia Take Home Naloxone; THN, Take Home Naloxone.

rush orders, and site enrolment numbers. These data are collected by THN sites and periodically faxed to BCCDC for manual entry into a database. Ambulance patient care reports are completed by paramedics and provided routinely by BC Emergency Health Services to BCCDC for the purpose of overdose surveillance. Overdose events were defined as ambulance-attended illegal drug overdoses following the BCCDC surveillance definition; ${ }^{10}$ overdose deaths were defined as ongoing or concluded coroners investigations for unintentional illicit drug deaths, following the definition used by the BC Coroners Service. ${ }^{11}$ The definition includes overdose deaths due to: (1) street drugs, (2) medications not prescribed to the decedent and (3) combinations of (1) and/or (2) with medications prescribed to the decedent. Deaths due to prescription opioids alone, excluding 1-3 were less than $5 \%$ and thus not included in the analysis.

The numbers of THN kits ordered and distributed, and the numbers of overdose events and overdose deaths, were tabulated by week for the complete years 2013-2017. Spearman correlations were used to assess associations among these variables in the same week and multivariate time-series analyses were used to investigate associations over time. Specifically, we used vector autoregressive moving average time-series models, which are the multivariate versions of standard autoregressive integrated moving average models, to assess lagged associations such as the impact of overdose events or deaths from prior weeks on number of kits ordered or distributed. Model fit and order selection were done using standard inspection of residuals and assessment of the Akaike information criterion (AIC). ${ }^{12}$ We considered models with lags of up to 8 weeks, but found that lags of $1-5$ weeks provided the best fit to these data based on diagnostics of the residuals and the AIC value. We used the first difference of the weekly numbers in our models to achieve stationary time series. Results were similar for both THN kits ordered and kits distributed to clients; here, we present only those for kits ordered, which is our primary analysis variable. We present results for the full data 2013-2017; similar results were found using only the most recent 3 years (2015-2017). All analyses were carried out in SAS V.9.4 (Proc CORR and Proc VARMAX). ${ }^{13}$ We did not find that numbers of overdose events or deaths were related to the number of kits ordered in previous weeks $(p>0.1$ in all cases). Full results from our time-series model are shown in online supplementary appendix A.

\section{Qualitative methods}

Study design

After creating a logic model for the THN programme (online supplementary appendix B), with assistance from stakeholders and conducting a literature review, we developed a semi-structured interview guide for each stakeholder group (table 1); see online supplementary appendix $\mathrm{C}$ for example questions. The questions explored perceptions on the challenges, barriers, facilitators and successes of the ramp up and were adapted iteratively as further individuals were interviewed. Interview guides were similar across stakeholder groups with the main differences being the depth of questions that were most relevant to that stakeholder's role. For example, BCCDC Pharmacy staff were asked to expand on supply chain management and the assembly of naloxone kits 
while BCCDC harm reduction staff were asked about data collection, surveillance, and site approval.

\section{Participant selection}

Participants were selected based on their involvement in the THN programme during the ramp up period between 1 November 2016 and 31 January 2017 (see the Quantitative results section). All BCCDC staff (pharmacy and harm reduction) and all regional harm reduction coordinators (HRC) involved with THN during the period of ramp up were invited through email or requested in person to participate in either a focus group or one-on-one interview. THN site coordinators (TSCs) were a convenience sample; coordinators who attended the June 2017 THN community advisory board meeting and who were involved in the programme during the ramp up period $(n=6)$ were invited to participate in an interview. Note that TSCs attending the community advisory board meetings are generally those that manage high-volume and high-risk sites, thus meeting our study criteria. Interviews with the TSCs were arranged by email.

Two focus groups $(n=9)$ and nine key informant interviews were conducted by two investigators (SY and SW) between May and August 2017. Focus group and key informant interviews lasted $30-60 \mathrm{~min}$ and were conducted in person or over the telephone according to the participant's preference. All focus groups and interviews were audiorecorded, transcribed verbatim and deidentified. Transcripts were made available to participants who wanted to comment and verify the information in their interview. Coauthors SY and SW independently analysed the data using an iterative qualitative descriptive method. ${ }^{14}$ Initial coding was informed by the interview guide but was refined iteratively as interviews and analysis provided new insights. Codes were grouped into similar descriptive categories based on the components of the programme, which captured variability between different stakeholders. The final themes were agreed on by the analysis team through consensus and the results were shared with participants and modified with their input to ensure their completeness and accuracy. A Standards for Quality Improvement Reporting Excellence reporting guideline was used. ${ }^{15}$

\section{RESULTS}

\section{Quantitative results}

In the 12 months following the declaration of the public health emergency in April 2016, BCTHN added 341 new THN distribution sites to the existing 155 sites. These new sites included 94 rural locations; of these 28 were First Nations sites. The number of kits ordered per month abruptly increased from 4688 in October 2016 to 9109 in November and plateaued at 11000 in December 2016 and January 2017 (figure 1). Thus, the 'ramp up' period, when BCTHN rapidly expanded its delivery and distribution capabilities to meet demand, is defined as 1 November 2016 to 31 January 2017. In the last 6 weeks of
2016, the weekly kit order was 20 times that of the same period in 2015 (2700 and 131 kits per week, respectively). During November/December 2016, there were 3 weeks with $>1500$ kits/week ordered by rush order. Rush orders are priority orders from kit-depleted high-volume sites that contact BCTHN staff to express an urgent need and hence strain BCCDC resources and impact routine orders from smaller sites. Standing orders are automatic weekly processing and delivery of an agreed on number of kits based on prior ordering patterns for high-volume sites. After implementation of standing orders, rush orders (10 month average) decreased from $27 \%$ to $4.0 \%$ of total kit orders (figure 2).

Numbers of THN kits ordered, overdose events and overdose deaths were all highly correlated within the same week during 2013-2017 ( $\mathrm{n}=261$ weeks; kits ordered vs overdose deaths: $r=0.76, p<0.001$; kits ordered vs overdose events: $r=0.82, p<0.001$; overdose events vs overdose deaths: $r=0.84, p<0.001)$. Time-series analysis showed a significant positive association between the number of kits ordered in a given week and the number of overdose events 1 week prior $(\beta=2.55, p=0.002)$ and the number of overdose deaths 2 weeks prior $(\beta=15.40, p=0.008)$. A weekly increase of 30 overdose events, for example, was associated with an average of $\sim 75$ additional kits ordered in the following week, whereas a weekly increase of 30 overdose deaths was associated with an average of $\sim 460$ additional kits ordered 2 weeks later. Similar associations were observed between the number of kits ordered and overdose events 3,4 and 5 weeks prior $(\mathrm{p}<0.05$ in each case) and between the number of kits ordered and overdose deaths 3 weeks prior $(\mathrm{p}=0.02)$.

Weekly numbers of overdose deaths were positively related to numbers of overdose events in the previous week ( $\beta=0.03, p=0.009)$ during 2013-2017. A weekly increase of 30 overdose events was associated with one additional overdose death in the following week, on average. We did not find that numbers of overdose events or deaths were related to the number of kits ordered in previous weeks ( $p>0.1$ in all cases).

\section{Qualitative results}

Eighteen key stakeholders were interviewed (table 1). All nine (100\%) BCCDC staff, six (55\%) of HRCs participated, and three of six (50\%) TSC attending the community advisory board meeting volunteered to participate. Two TSCs were from sites on the mainland of BC, one of which provided services to youth, the third TSC was from Vancouver Island. The key findings are shown in table 2. Participants' responses were divided into two main themes: (1) successes and (2) challenges and facilitators; the latter were grouped into four subthemes.

\section{Successes}

Stakeholders' responses were positive and portrayed a sense of pride that the programme was able to respond to demand and ramp up rapidly with minimal additional resources. Despite a 20-fold increase in demand, 


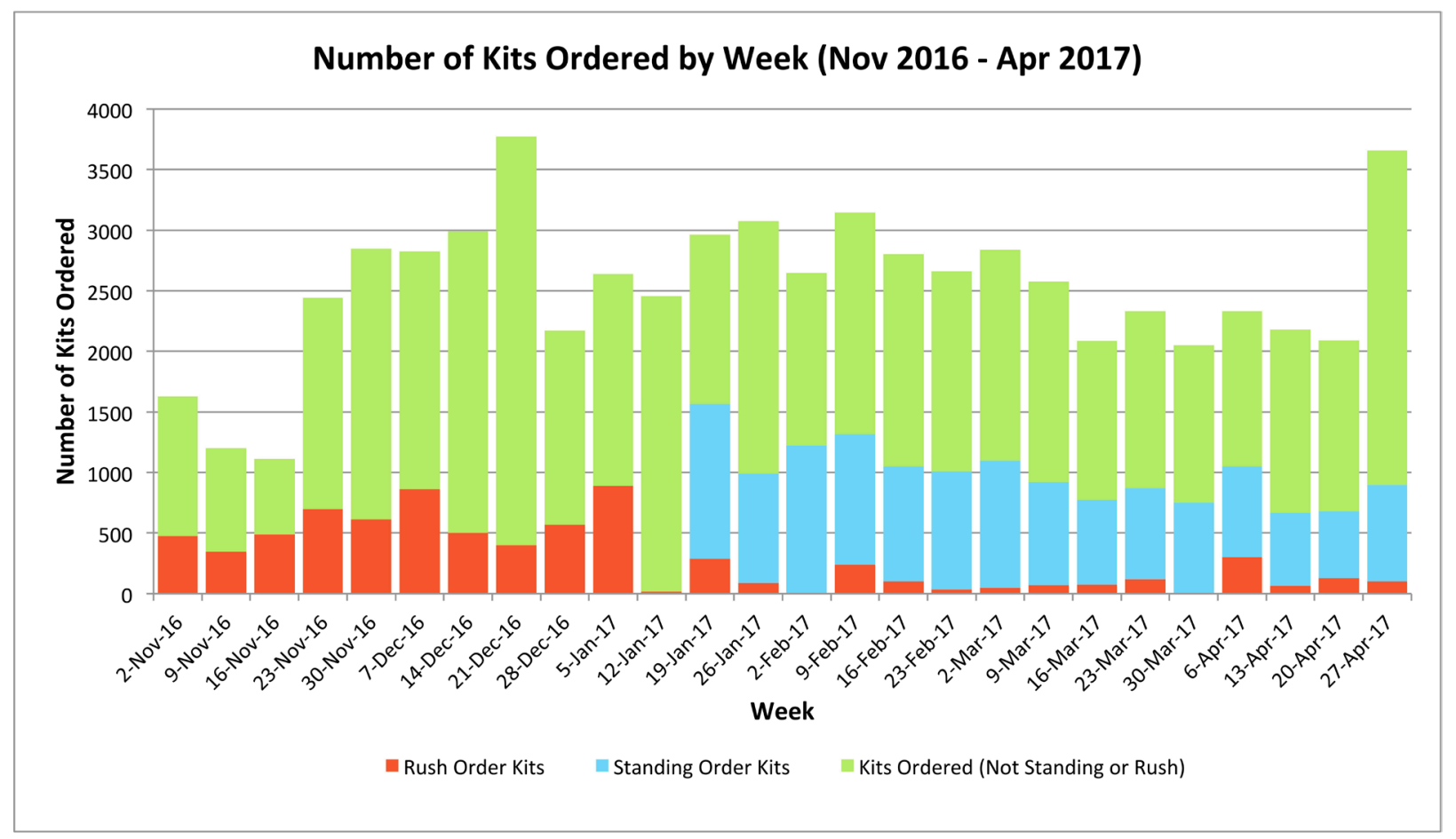

Figure 2 A graphical representation of the number and type of naloxone kit orders from 2 November 2016 to 27 April 2017.

participants reported that BCCDC was able to deliver kits to sites within 10 working days of receiving the faxed order. Clear communication and established relationships between stakeholders enabled rapid problem solving. On occasions when large orders were received which strained capacity, the BCCDC clarified the need with the site and partial orders were shipped; if an urgent same day request was received from outside the lower mainland, then BCCDC worked with HRCs to transfer kits from a nearby site. HRCs and TSCs commented that the THN programme helped to instil a culture of harm reduction, build relationships with community groups and empower programme participants.

\section{Challenges and facilitators}

Despite these successes, the ramp up period was a time of stress on the programme and staff, as it was not resourced to respond to the sudden unexpected increase in demand.

\section{Production and distribution of kits}

The production of naloxone kits in BC was identified as an operational bottleneck limited by manpower and funding. Kit components were ordered individually and assembled by staff in the BCCDC Pharmacy. The unpredictable nature of substances available in the illicit drug market and subsequent risk of overdose events limited the ability of the programme to forecast demand and adjust production capacity ahead of time.

In October 2016, BCCDC outsourced kit production (without naloxone) to an external company, so that only the placement of naloxone into the kit took place at BCCDC. Due to the unforeseen demand in November 2016, the initial contractor was unable to meet the volume of orders. Though this was a major setback, it was later resolved by outsourcing to a different contractor and having the initial contractor as back up, thus enabling the programme to meet demand.

\section{Policy changes}

Federal, provincial and programme-wide policies also impacted client access to naloxone. A timeline of the relevant policy changes is shown in figure 3. In March 2016, Health Canada removed naloxone from the Prescription Drug List (figure 3), which enabled the expansion of kit eligibility beyond people at risk of an overdose to those at risk of witnessing an overdose including friends and family of PWUD. At the provincial level, each college of pharmacists chose how to schedule naloxone; either schedule II-behind the counter which necessitated an interaction with the pharmacist, or unscheduled (over the counter). Initially, the College of Pharmacists of BC chose schedule II; but in September 2016 further changed the status of naloxone to unscheduled which allowed it to be available anywhere and accessible by anyone. Participants noted that prior to the scheduling changes, the prescription-only status of naloxone required a physician or nurse practitioner to prescribe each kit and collect patient information, which restricted access of clients who often wished to remain anonymous. New organisational policies allowed low-barrier peer resource centres without healthcare professionals onsite to become THN sites, improving kit accessibility to PWUD.

To streamline the ordering process, a programme-wide policy of standing orders was introduced in January 2017. A standing order is an automatic weekly delivery for sites that regularly order a high volume of kits. This policy improved the efficiency of the programme and, as shown in figure 2, 
Table 2 Summary of the qualitative results: successes,challenges/barriers and facilitators

\section{Successes}

Responsiveness and dedicated team

- Responsive to ongoing situations and needs; responded to 20 -fold increase in demand over 12 months

'The program has been really good at adapting and evolving based on what we hear on the ground ... from our harm reduction coordinators from the sites, from information we learn on our overdose forms, from involvement of peers through HRSS. We let that drive the program which I think is hugely successful ... it means that the program stays relevant'. (BCCDC Harm Reduction Staff 4)

'I think the fact that we were able to increase in size so rapidly and go from 150 kits a week to almost 3000 a week in a year with really not many more resources was a huge, huge success'. (BCCDC Harm Reduction Staff 4)

- Able to meet commitment of distribution of kits within 10-working day policy

'There were a number of occasions where there would be a bad batch of drugs and an extraordinary number of overdoses in a very short period of time. And we were able to get Naloxone same day from-like, hundred kits same day from BCCDC. So I felt like they did a pretty good job of supplying our sites with kits'. (Harm Reduction Coordinator 3, urban)

Partnerships and relationships

- Reaching underserved and rural communities

'I think that the ability to expand into rural areas was really effective and a lot of that was done through partnership with First Nations health and a lot of it was done through public health units in more rural areas'. (BCCDC Harm Reduction Staff 3)

- Engaging organisations to introduce harm reduction principles

[Naloxone has] instill[ed] a culture of harm reduction and a better understanding of issues like stigma and kind of the bigger picture for some of the stuff'. (Harm Reduction Coordinator 6, urban)

'[Being a THN site has] been a really incredible opportunity for us to connect with community groups that we maybe didn't have relationships with before ... it has helped us build relationships and also really helped us have conversations with organizations who have typically come from a very abstinence-based approach or weren't willing to have conversations about working with PWUD before'. (THN Site Coordinator 1, rural

Empowerment

- Saving lives and reducing stigma

'I think the successes have been how many lives have been saved. And how empowering it has been and what a way to engage people who obviously often feel stigmatized and will continue to feel stigmatized as long as drugs remain illegal—really kind of helping folks feel like they can do something in the midst of this crisis'. (THN Site Coordinator 2, urban)
2. Challenges/barriers
Facilitators

(i) Production and distribution of kits

\section{- Inability to forecast demand}

'This [crisis] caught us completely flatfooted. Like ... nobody really talked about harm reduction kits a year ago ... And then all of a sudden this is like the hot-button issue'. (BCCDC Pharmacy Staff 1)

- Limited personnel and funding to produce kits in-house

Limited storage space at BCCDC for naloxone and other kit supplies

- Failure of outsource company to meet on kit orders

\section{- Funding approval for labour}

'Human resources helped unclog the bottleneck we had'. (BCCDC Pharmacy Staff 2)

- Pharmacy staff willingness to work overtime and others helping to assemble kits

'Pharmacists themselves were put(ting] the kits together through overtime (....)we had students helping to put kits together. We had kit-making lunchtime parties where people from around BCCDC would come and put the kits together'. (BCCDC Harm Reduction Lead)

- Outsourcing of kit assembly

- Implementation of standing orders

Contracting low naloxone kit component prices prior to crisis

\section{(ii) Policy changes}

\section{- Rush orders placed strain on pharmacy}

\section{- Prescription-only status of naloxone}

'One of the [barriers] when the ramp-up started was that Naloxone was still a scheduled drug. So it had to go through the pharmacy and the pharmacy had to check it off. We also had to make sure that on the kits we had the date when-the expiry date. And, of course, initially we-before it became unscheduled we used to have to put people's names on it. We used to have to collect that information'. (BCCDC Harm Reduction Lead)

\section{- Implementation of standing orders for high-volume sites}

- Federal descheduling of naloxone in March 2016 and provincial descheduling in September 2016

'When [naloxone] became unscheduled, we [no longer] needed to keep long list of people's names because it wasn't a drug that needed to be prescribed .... that simplified things and reduced the amount of data that the sites had [to collect)'. (BCCDC Harm Reduction Staff 2)

\section{(iii) Administration and data surveillance}

- Insufficient manpower for administrative tasks created backlog

- Limitations of fax/paper-based system

'The [paper-based] database was sort of designed for 20 sites and now we have 500-something sites'. (BCCDC Harm Reduction Staff 3)

- Real-time surveillance was unavailable during ramp up'Because our database was designed for such a small program and because we were such a small team, the required paperwork for the program, the dispensing records, the training records, it just literally just piled up. We became months behind [in data entry).... which meant that our surveillance information was behind as well'. (BCCDC Harm Reduction Staff 4) 


\section{Table 2 Continued}

(iv) Naloxone training

- High number of TSC staff who needed to be trained

- Provincial directive requiring all emergency departments (EDs) and public health units (PHU) to provide $\mathrm{THN}^{16}$

- Geographical barriers in training staff across health authorities 'Training, especially in our rural and remote communities, has been exceptionally difficult.... we [2 people] have to cover the whole darn health authority which is very vast'. (Harm Reduction Coordinator 1 , rural)

- Addressing stigma associated with illicit drugs and harm reduction principles'(We need to] make sure that people are really wanting Naloxone but they're not prepared to operate from a harm reduction framework or they're not able to address some of the stigmatizing language that they perpetuate in some of their training. And not really ready to look at some of their organizational policies that exacerbate risk'. (Harm Reduction Coordinator 2, rural)

- Concerns around quality control of training'Our ability to do quality control [on the training] is compromised [as a result of the ramp up)'. (Harm Reduction Coordinator 3, urban)
- Online resources, for example, QuickLearn, Naloxone App improved ease of training ${ }^{16-18}$

- Train-the-trainer model

Clinical nurse educators helped organise and train staff at EDs and PHUs

Inclusion of those with lived experience as naloxone trainers

' 50 percent of the workforce [of trainers] should be people with lived experience. I'm just really sort of fore fronting that as change-as a key strategy in terms of changing the system is us creating positions and space for those folks [with lived experience] to lead the work'. (Harm Reduction Coordinator 4, urban)

BCCDC, British Columbia Centre for Disease Control; THN, Take Home Naloxone; TSC, THN Site Coordinator.

reduced the number of rush orders, which were placing a strain on BCCDC administrative and pharmacy staff and impacting routine orders from smaller sites.

Scheduling changes also enabled the Facility Overdose Response Box programme to be introduced in December 2016. The aim is to support staff at non-profit community-based organisations such as shelters, supportive housing and friendship centres to respond to overdoses. ${ }^{16}$ The boxes, supplied and replenished by BCCDC, contain multiple ampules of naloxone and other supplies so that staff can respond to overdoses without the need to regularly replace individual kits from THN sites. To participate, organisations commit to developing an overdose response policy and protocol, provide staff training and debriefing and report data to BCCDC.

\section{Administration and data surveillance}

BCCDC harm reduction staff reported that during the ramp up, increasing site queries and paperwork placed a strain on programme staff. Paperwork from site applications, kit orders and distribution data were received through fax and manually entered into a database. Forms that were not entered into the database accumulated and led to challenges of having timely programme information available. This was temporarily resolved by hiring additional administrative staff. As a long-term solution, a database is being developed to enable sites to order kits and enter data online which will help to manage site inventory, allow sites to produce their own reports and improve real-time monitoring and surveillance. It will place accountability on site staff to enter their own data and reduce the burden of data entry at BCCDC.

\section{Naloxone training}

BCTHN participants are taught how to recognise and respond to opioid overdoses and administer naloxone prior to receiving a kit. BCCDC develops training materials in consultation with HRCs, who organise training for THN educators and site staff in their respective health authorities. With over 300 sites joining BCTHN programme in 2016 and provincial directives mandating all emergency departments and public health units to

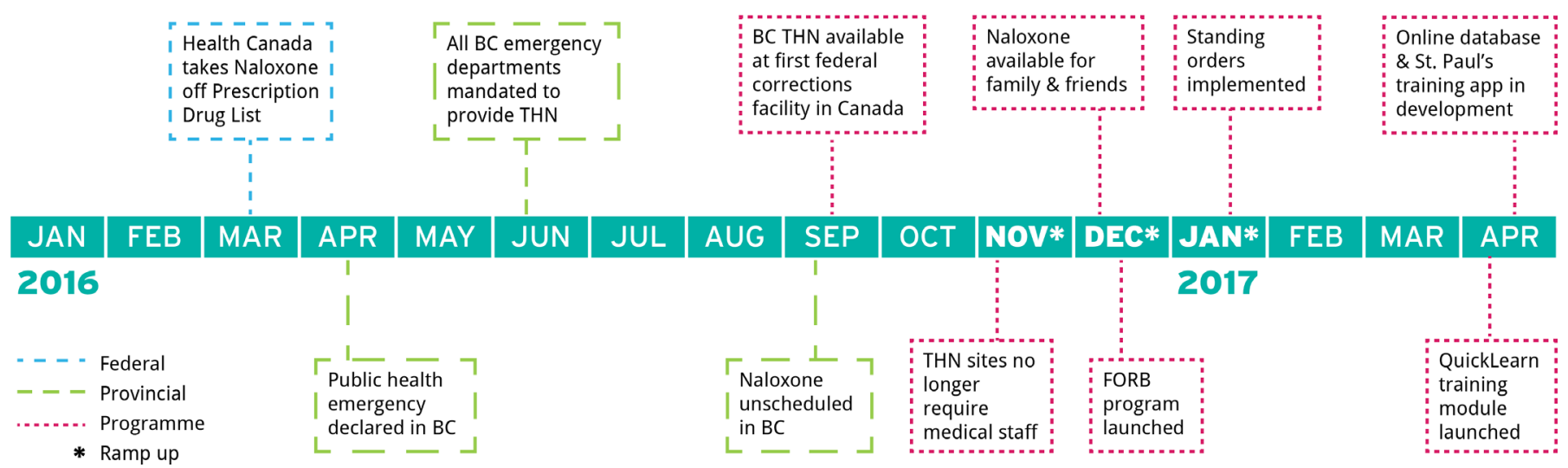

Figure 3 Timeline of key policy changes and developments of the THN programme in 2016 and 2017. BC, British Columbia; FORB, Facility Overdose Response Box; THN, Take Home Naloxone. 
offer THN (figure 3), it became an insurmountable challenge' to respond to the number of staff training requests. Large emergency departments had hundreds of nurses with limited availability due to shift work. To reach staff, the HRCs utilised clinical nurse educators in a trainthe-trainer model. The development of online training resources such as Naloxone Training app and QuickLearn module ${ }^{17} 18$ improved the consistency of training, and site staff reported them to be accessible and easy-to-use when training clients. HRCs suggested that opportunities should be created for more peers to be involved with training both clients and staff, as a strategy of reducing stigma and creating role models for PWUD.

Other concerns mentioned by participants included reaching staff in some rural and remote communities across health authorities. HRCs also reported difficulties in training staff from organisations that were traditionally abstinence-based and unsupportive of harm reduction principles. Although this was reported as a barrier, it was seen by other HRCs as an opportunity to engage organisations in harm reduction principles and address stigma.

\section{DISCUSSION}

The opioid crisis has been relentlessly on the rise across Canada and the USA, and also affecting parts of Europe, Australia, Africa and the Middle East. ${ }^{19-21}$ Combatting the opioid crisis requires a multipillar approach, including measures of prevention, treatment, law enforcement and harm reduction. ${ }^{22}$ However, naloxone remains the single most effective tool for reversing opioid overdose.

As of 15 June 2019, around 1590 sites distribute THN across BC, including 20 correctional facilities, 150 First Nations sites, 86 hospitals and emergency departments and 656 community pharmacies. ${ }^{23}$ Not only is there great demand for naloxone kits, the rate of kit utilisation is also high. Wheeler et al reported that the utilisation rate of naloxone kits from 1996 to June 2014 in the USA was $17.4 \% .{ }^{24}$ In comparison, from initiation of the BCTHN programme to the end of 2018, 147028 kits have been distributed with 40828 kits used to reverse an overdose. ${ }^{23}$ This represents an overall $28 \%$ rate of kit utilisation, suggesting that these kits are being distributed to a highly at-risk population. Note that this does not take into account more than 25000 kits reported lost, confiscated or replaced as expired. ${ }^{23}$

We found a strong positive association between the number of illicit drug overdose deaths (also overdose events) in a given week and the number of naloxone kit orders in the same week and over subsequent weeks (figure 1). It is likely that the media reports of deaths, increased response of paramedics and heightened public awareness contribute to increasing the demand for naloxone kits in the community. We demonstrate that an increase in overdose events and deaths predict kit orders, on average, a week or two later. Demand associated with overdose events can persist up to 5 weeks after the events. A short lag time as such requires that THN programmes have the capacity to ramp up at short notice. As the opioid crisis sweeps across Canada and the USA, it becomes increasingly important for public health programmes to be able to rapidly expand their capacity to distribute naloxone. Our approach using multivariate time series models also allowed us to assess the population-level association between kit orders and subsequent overdoses. Consistent with previous studies, we did not find that the number of kit orders predicted the number of overdose events or deaths in subsequent weeks. ${ }^{25}$ However, mathematical models comparing the observed ramp up of THN with counterfactual scenarios (eg, no THN programme) suggest that more than 1500 deaths were averted in $\mathrm{BC}$ during 2012-2017 as a result of the THN programme. ${ }^{26}$

The BCTHN programme was able to respond rapidly to the overdose crisis to meet demand because of established close relationships and communication with HRCs and THN sites that allowed the programme to closely monitor the increases in overdoses and the rapidly changing situation. Outsourcing the assembly of naloxone kits to contractors also has the potential to improve efficiency and gain additional storage capacity for stand-by supplies; however, it is crucial to ensure that the contractor is able to meet spikes in demand.

Modifications in law and policies surrounding drug scheduling and handling also helped facilitate the ramp up (figure 3). In particular, the removal of naloxone from the Prescription Drug List in 2016 had multiple downstream effects that improved client access to naloxone and enabled better efficiency and expansion of BCTHN. Similar policy changes have also been made in the UK and USA in order to facilitate better access and scaling of naloxone services. ${ }^{27}$ Since October 2015, people working in or for drug services in the UK have been able to provide naloxone without a prescription. ${ }^{27}$ Naloxone access laws have also been put in place in various states in the USA, and are on average, associated with an average increase of $79 \%$ in naloxone dispensed from US retail pharmacies. ${ }^{28}$

Many of the challenges during the BCTHN ramp up were related to a paper and fax-based ordering and data-collection system. For example, as the number of sites and site applications spiked, programme administrators were met with more paperwork than they could handle. Even with additional staff hires, physical data entry became an unexpected barrier. As a result, a common theme in interviews with BCTHN staff was the need for the development and transition to an online database into which TSCs can themselves place orders and input kit distribution and usage. BCTHN is in the middle of such a transition, and this change is hoped to reduce administrative burden and aid in ongoing programme monitoring and surveillance. A future direction of research would be to evaluate the outcomes of implementing such an online database.

BCTHN employed a train-the-trainer model. Previously, the train-the-trainer model for disseminating knowledge has been successful in other disciplines such as medical communication skills ${ }^{29}$ and training healthcare workers of people with HIV/AIDS. ${ }^{30}$ However, it has been implemented 
in naloxone training with mixed results. In our study, both HRCs and TSCs were generally positive about the train-thetrainer model and similar to a Norwegian study reported that the model was effective for knowledge translation and efficiently training a high volume of staff during THN programme expansion. ${ }^{31}$ However, in the UK, this method was not completely successful ${ }^{32}$; Mayet et al cited examples of perceived barriers to the train-the-trainer model including caseload issues, clinicians with schedules too busy to take time to train clients, and clinicians feeling that they needed more training or refresher training. ${ }^{32}$ To address these barriers, BCTHN developed the online QuickLearn module to assist training of site staff and is also available to refresh their knowledge. ${ }^{18}$ In recognition of a concern about the varying quality of client training, the BCTHN in collaboration with staff at a Vancouver emergency department developed an online application to enhance standardisation of client training. ${ }^{17}$ Further research is needed to validate the THN train-the-trainer model using post-training questionnaires and assessments as in Mayet et al. ${ }^{32}$

In addition to providing naloxone, BCTHN has provided an opportunity to connect with community groups and build new relationships and partnerships. ${ }^{33}$ It has been described by HRCs as an 'incredible opportunity' to introduce harm reduction principles to organisations that traditionally have an abstinence-based approach. In previous programme evaluations, clients have reported feelings of empowerment and a strong sense of pride for participating in the THN programme, which is consistent with feelings of pride from the success of THN in this study. ${ }^{334}$

\section{Limitations of study}

This study describes specific details and contexts of BCTHN's ramp up, some of which may not apply to programmes in other provinces, though we hope other THN programmes can take away something from our experience.

Our quantitative analysis showed time-series relationships among THN programme activity, overdose events and deaths; however, these statistical associations do not necessarily imply direct causal relationships. Further work is needed to understand the mechanism by which THN programme activity responds to changes in overdose events and deaths over time.

The aim of the study was to examine the challenges and successes experienced during the ramp up from the perspective of staff and stakeholders. We interviewed all BCCDC staff and the majority of HRCs involved with the ramp up; however, only a small number of TSCs were interviewed and thus the opinions of TSCs interviewed may not be representative of all their peers. We interviewed TSCs from BC mainland, Vancouver Island and a youth-specific site; however, all were from largevolume sites. Our study focused on staff experiences since client experiences have been well studied in previous programme evaluations. ${ }^{39}$

To avoid perceived conflicts of interest that could bias responses, interviews were performed by student researchers who are not programme employees and all responses were anonymised. Student researchers SY and SW were supervised by JB in study design, methodology and appraisal of themes through regular discussions during in-person meetings and email. The researchers involved in the qualitative analysis attempted to minimise any bias in the coding and appraisal of themes and opinions expressed in interviews through independent coding, discussion, developing consensus and reflexivity and validating results with study participants.

\section{CONCLUSION AND RECOMMENDATIONS}

In conclusion, with opioid death rates continuing to increase in North America and many parts of the world, ${ }^{1}$ we strongly recommend that THN programmes plan ahead and have the tools to be able to respond to sudden spikes in overdose deaths and naloxone demand. As such, we are making the following recommendations based on our analysis of the BCTHN ramp up:

- Have sufficient financial resources for supplies and staffing, including surge capacity as it is difficult to accurately predict unexpected increases in demand.

- Descheduling of naloxone at a provincial or national level has been shown to improve client access and scaling of THN programmes.

- Outsource kit production but assess the contractor's kit production capability and have back-up plans in case a contractor is unable to meet orders when increased demand occurs.

- Implement standing orders for sites with regular highvolume orders to reduce rush orders and to ensure that the demand is consistently met.

- Monitor overdose event and/or death trends, which are both predictive of future naloxone demand (with a lag time of 1-2 weeks in our study).

- Consider implementing an online database at the outset or transitioning to one as early as possible so as to prevent issues with scaling the programme as it grows and to ensure monitoring and timely surveillance.

- Utilise a train-the-trainer model and have an online curriculum to improve consistency and reach of training.

- Support people with lived experience to be naloxone trainers as this will improve acceptability of training and contribute towards reducing stigma against PWUD.

Acknowledgements We would like to thank all the participants for the time they contributed to this investigation and would also like to acknowledge Emily Ogborne Hill for assistance in participant recruitment and Margot Kuo for assistance in creation of the logic model.

Contributors SY and JB were responsible for the study design. SY was responsible for the literature review. SY and SW conducted the qualitative interviews and focus groups. SY, SW and JB were responsible for the qualitative analysis. MO and JL were responsible for the quantitative analysis. SY wrote the manuscript draft with significant contributions from $\mathrm{M} 0$ and JB. All of the authors critically revised the manuscript, approved the final version submitted for publication and agreed to act as guarantors of the work. 
Funding The BC Take Home Naloxone programme is funded by the BC Centre for Disease Control. SW and JL received the Dr James Rossiter MPH Practicum Award. Competing interests None declared.

Patient consent for publication Written informed consent was obtained from all focus group and interview participants.

Ethics approval Ethics approval was obtained from the University of British Columbia Behavioural Ethics Board (H12-02557).

Provenance and peer review Not commissioned; externally peer reviewed.

Data availability statement Data are available in a public, open access repository.

Open access This is an open access article distributed in accordance with the Creative Commons Attribution Non Commercial (CC BY-NC 4.0) license, which permits others to distribute, remix, adapt, build upon this work non-commercially, and license their derivative works on different terms, provided the original work is properly cited, appropriate credit is given, any changes made indicated, and the use is non-commercial. See: http://creativecommons.org/licenses/by-nc/4.0/.

\section{REFERENCES}

1 WHO. Information sheet on opioid overdose. who. Available: http:// www.who.int/substance_abuse/information-sheet/en/ [Accessed 14 Dec 2017].

2 Strang J, Darke S, Hall W, et al. Heroin overdose: the case for takehome naloxone. BMJ 1996;312:1435-6.

3 Banjo O, Tzemis D, Al-Qutub D, et al. A quantitative and qualitative evaluation of the British Columbia take home naloxone program. CMAJ Open 2014;2:E153-61.

4 Chronister KJ, Lintzeris N, Jackson A, et al. Findings and lessons learnt from implementing Australia's first health service based takehome naloxone program. Drug Alcohol Rev 2018;37:464-71.

5 Wheeler E, Davidson PJ, Jones TS, et al. Community-based opioid overdose prevention programs providing naloxone - United States, 2010. MMWR Morb Mortal Wkly Rep 2012;61:101-5.

6 McDonald R, Strang J. Are take-home naloxone programmes effective? systematic review utilizing application of the Bradford Hill criteria. Addiction 2016;111:1177-87.

7 Public Health Agency of Canada. National report: apparent opioidrelated deaths in Canada (January 2016 to March 2017). Gov. can, 2017. Available: https://www.canada.ca/en/public-health/services/ publications/healthy-living/apparent-opioid-related-deaths-report2016.html\#fig1 [Accessed 14 Dec 2017].

8 BC Centre for Disease Control. Public health emergency in bc. Available: http://www.bccdc.ca/about/news-stories/stories/publichealth-emergency-in-bc [Accessed 14 Dec 2017].

9 Deonarine A, Amlani A, Ambrose G, et al. Qualitative assessment of take-home naloxone program participant and law enforcement interactions in British Columbia. Harm Reduct J 2016;13:17.

10 Paramedic attended overdose events, 2018. Available: http:// www.bccdc.ca/resource-gallery/Documents/Statistics\%20and\% 20Research/Statistics\%20and\%20Reports/Overdose/BCAS indicator_public.pdf [Accessed 7 Jan 2018].

11 Coroners Service. Illicit Drug Overdose Deaths in BC January 1, 2008 - March 31, 2018, 2018. Available: https://www2.gov.bc.ca/assets/ gov/birth-adoption-death-marriage-and-divorce/deaths/coronersservice/statistical/illicit-drug.pdf [Accessed 4 Jun 2018].

12 Brocklebank JC, Dickey D, Choi B. SAS for forecasting time series. 3rd edn. Cary, NC: SAS Instutitute Inc, 2018.

13 SAS Institute Inc. Base SAS® 9.4 procedures guide: statistical procedures. 2nd edn. Cary, NC: SAS Institute Inc, 2013.

14 Sandelowski M. Whatever happened to qualitative description? Res Nurs Health 2000;23:334-40.
15 Ogrinc G, Davies L, Goodman D, et al. Squire 2.0 (standards for quality improvement reporting excellence): revised publication guidelines from a detailed consensus process. BMJ Qual Saf 2016;25:986-92.

16 History of take home naloxone. heart. Available: https:// towardtheheart.com/infographics [Accessed 21 Feb 2019].

17 Naloxone Training App. Take home naloxone. Available: http://www. naloxonetraining.com [Accessed 6 Jan 2018].

18 Quick-Learn. Bc take home naloxone. Available: http:// towardtheheart.com/naloxone-course [Accessed 5 Jan 2018].

19 Response to the opioid crisis. Available: http://www.unodc.org/ unodc/en/opioid-crisis/index.html [Accessed 5 Nov 2018].

20 Public Health Agency of Canada. National report: apparent opioidrelated deaths in Canada (released March 2018). Gov. can, 2018. Available: https://www.canada.ca/en/public-health/services/ publications/healthy-living/national-report-apparent-opioid-relateddeaths-released-march-2018.html [Accessed 24 Apr 2018].

21 CDC injury center. Drug overdose death data, drug overdose, 2018. Available: https://www.cdc.gov/drugoverdose/data/statedeaths.html [Accessed 5 Nov 2018].

22 Goverment of canada. Federal action on opioids. AEM, 2017. Available: https://www.canada.ca/en/health-canada/services/ substance-use/problematic-prescription-drug-use/opioids/federalactions.html [Accessed 5 Nov 2018].

23 Toward The Heart. Available: http://towardtheheart.com/ [Accessed 13 Dec 2017].

24 Wheeler E, Jones TS, Gilbert MK, et al. Opioid Overdose Prevention Programs Providing Naloxone to Laypersons - United States, 2014. MMWR Morb Mortal Wkly Rep 2015;64:631-5.

25 McAuley A, Bouttell J, Barnsdale L, et al. Evaluating the impact of a national naloxone programme on ambulance attendance at overdose incidents: a controlled time-series analysis. Addiction 2017;112:301-8.

26 Irvine MA, Kuo M, Buxton JA, et al. Modelling the combined impact of interventions in averting deaths during a synthetic-opioid overdose epidemic. Addiction 2019;114:1602-13.

27 GOV.UK. Widening the availability of naloxone. Available: https:// www.gov.uk/government/publications/widening-the-availability-ofnaloxone/widening-the-availability-of-naloxone [Accessed 18 Jun 2019].

28 Xu J, Davis CS, Cruz M, et al. State naloxone access laws are associated with an increase in the number of naloxone prescriptions dispensed in retail pharmacies. Drug Alcohol Depend 2018;189:37-41.

29 Draper J, Silverman J, Hibble A, et al. The East Anglia Deanery communication skills teaching Project-six years on. Med Teach 2002;24:294-8.

30 Giusti A, Conti S, Di Lorenzo G, et al. [How Italian midwives contribute to breastfeeding promotion: a national experience of 'cascade' training]. Ig Sanita Pubbl 2006;62:53-67.

31 Madah-Amiri D, Clausen T, Lobmaier P. Utilizing a train-the-trainer model for multi-site naloxone distribution programs. Drug Alcohol Depend 2016;163:153-6.

32 Mayet S, Manning V, Williams A, et al. Impact of training for healthcare professionals on how to manage an opioid overdose with naloxone: effective, but dissemination is challenging. Int J Drug Policy 2011;22:9-15.

33 City Of Vancouver. City and partners host naloxone and overdose response training event, 2016. Available: http://vancouver.ca/newscalendar/city-and-partners-host-naloxone-and-overdose-responsetraining-event.aspx [Accessed 30 Mar 2018].

34 Mitchell K, Durante SE, Pellatt K, et al. Naloxone and the inner City youth experience (NICYE): a community-based participatory research study examining young people's perceptions of the bc take home naloxone program. Harm Reduct J 2017;14:34. 